ESPAÇO TEMA LIVRE

\title{
Vulnerabilidades cruzadas: as mulheres e suas experiências diversificadas
}

\author{
Luana Passos ${ }^{1}$ \\ http://orcid.org/0000-0002-5470-7349
}

\author{
Lorena Souza ${ }^{2}$ \\ https://orcid.org/0000-0002-3577-4984
}

${ }^{1}$ Universidade Federal do Oeste da Bahia, Centro das Humanidades, Barreiras, BA, Brasil

${ }^{2}$ Universidade Federal do Recôncavo da Bahia, Centro de Ciências Agrárias, Ambientais e Biológicas, Programa de PósGraduação em Recursos Genéticos Vegetais, Cruz das Almas, BA, Brasil

\section{Vulnerabilidades cruzadas: as mulheres e suas experiências diversificadas}

Resumo: Este artigo objetiva investigar as vulnerabilidades cruzadas que marcam as mulheres enquanto sujeito multifacetado. Priorizou-se, para tanto, indicadores de mercado de trabalho e de provisão de cuidados. A metodologia utilizada se deu a partir da análise descritiva dos dados da Pesquisa Nacional por Amostra de Domicílios Contínua, de 2018. Os achados apontam que as mulheres negras, pobres e as negras pobres, em linhas gerais, apresentam maior vulnerabilidade. Portanto, em que pese as normas de gênero alcançarem todas as mulheres, os dados evidenciam que os efeitos comportam gradações de acordo com a cor e a classe social a qual elas fazem parte.

Palavras-chave: Mulheres. Vulnerabilidades. Mercado de trabalho. Cuidados.

\section{Crossed vulnerabilities: women and their diverse experiences}

Abstract: This article aims to investigate the cross vulnerabilities that mark women as a multifaceted subject. For that, priority was given to labor market and care provision indicators. The methodology was the descriptive analysis of data from the National Continuous Household Sample Survey, of 2018. The findings indicate that black, poor women and poor black women, in general, are more vulnerable. Therefore, despite the gender norms reaching all women the data show that the effects are graded according to the color and social class to which they belong.

Key words: Women. Vulnerabilities. Labor Market. Care.

Recebido em 14.04.2020. Aprovado em 24.06.2020. Revisado em 14.10.2020.

(c) (\$) Este é um artigo publicado em acesso aberto (Open Access) sob a licença Creative Commons Attribution NonBY NC Commercial, que permite uso, distribuição e reprodução em qualquer meio, sem restrições desde que sem fins comerciais e que o trabalho original seja corretamente citado. 


\section{Introdução}

As mulheres tiveram sua participação no mercado de trabalho e sua atuação fora da família constrangidas, devido às atribuições sociais que lhes conferiram a função de cuidadoras do lar na contrapartida da provisão financeira dos maridos. Embora o modelo de homem provedor e mulher cuidadora não seja mais a marca das sociedades ocidentais, as assimetrias de papéis sociais permanecem, fazendo com que as mulheres tenham sua trajetória marcada por vulnerabilidades.

As evidências são contundentes em relação às limitações que a mulher enfrenta em sua sociabilidade ora devido às próprias responsabilidades familiares que elas assumem, ora pela discriminação e preconceito que modulam relações no mercado de trabalho, ora pela sobreposição dos efeitos domésticos e discriminatórios.

Tem de se destacar, no entanto, as desigualdades entre as mulheres. A realidade revela uma experiência social diversificada feminina, o que coloca em xeque a ideia de categoria homogênea que por longa data orientou a ação do movimento feminista. $O$ feminismo negro teve nesse percurso, de questionamento da homogeneidade das mulheres, um proeminente papel. As feministas negras questionaram o feminismo vigente dado que, a despeito de perceber as inter-relações entre gênero e classe, desconsiderava outras relações relevantes como o racismo na definição de desigualdades.

Interseccionar gênero, raça e classe presta, portanto, uma avultada contribuição no entendimento de como outros fatores identitários organizam, ou até mesmo hierarquizam, as experiências sociais. Ter as mulheres como categoria homogênea pode escamotear no privilégio de algumas as desigualdades latentes na vida de tantas outras, sendo relevante desnudar as assimetrias entre as mulheres e buscar seu enfrentamento tanto quanto o embate das dissimetrias de gênero. Posto isso, o objetivo deste artigo é investigar as vulnerabilidades cruzadas que marcam as mulheres enquanto sujeito multifacetado, priorizando indicadores de mercado de trabalho e de provisão de cuidados. Como metodologia se acessará a análise descritiva dos dados da Pesquisa Nacional por Amostra de Domicílios Contínua, do ano de 2018.

O artigo está dividido em duas seções além desta introdução e das considerações finais. Na primeira seção se discute as interfaces entre gênero, raça e classe como princípios organizadores na vida das mulheres. E, na segunda seção são apresentados dados brasileiros que corroboram a experiência diversificada das mulheres no mercado de trabalho e na função de cuidar.

\section{Interfaces entre gênero, raça e classe: mulher como sujeito multifacetado}

Em sintonia com a ideia de que as diferenças biológicas definem as habilidades, modularam-se socialmente funções assimétricas de acordo com o sexo. Sendo assim, as relações sociais circunscreveram as aptidões femininas ao espaço privado e as masculinas a vida pública, perpetuando-se por gerações a obrigação moral da mulher com a família e a dos homens com as responsabilidades de provisão material.

A gênese da concepção de que certas atividades são produtivas e outras reprodutivas ampara-se justamente na definição de espaços e funções sociais díspares conforme o sexo. A distinção entre produção e reprodução é uma forma de afirmar as diferenças sociais nas peculiaridades biológicas, de forma a designar às mulheres, as únicas capazes de reprodução biológica, as atividades reprodutivas e aos homens, que fisicamente não dispõem dessa habilidade, as tarefas produtivas. Cabe lembrar que não se trata apenas de um processo de diferenciação, mas também de hierarquização no qual a produção, desempenhada pelos homens, apresenta maior relevância social que as atividades que são entendidas como de reprodução, prioritariamente femininas.

Essas atribuições sociais tiverem como efeito a vivência por parte das mulheres de uma posição social mais precarizada, em especial nas relações de trabalho. Claramente, os estudos sobre gênero e trabalho participam da concepção de que a divisão sexual do trabalho não apenas atravessa as relações sociais como é fundamental na sua organização (BIROLI, 2016), sendo orientada por dois princípios: "o de separação (existem trabalhos de homens e outros de mulheres) e o da hierarquização (um trabalho de homem 'vale' mais do que um trabalho de mulher)" (KERGOAT, 2009, p. 67).

A divisão sexual do trabalho tem, portanto, caráter estruturante que se ancora na definição assimétrica de função conforme o sexo, podando a escolha das mulheres em suas possibilidades de ação. A responsabilidade atribuída a mulheres e homens, em muito, se fundamenta em uma forma de gerir a vida em sociedade em 
conformidade às aptidões ditas como naturais para os sexos. Todavia, cabe ponderar que, a despeito dos prejuízos sociais comuns às mulheres, raça e classe comparecem como atributos diferenciadores ou potencializadores de desvantagens. As análises a respeito das relações sociais de sexo e as relações de classe e raça sempre se deram de forma antagônica. Por muito tempo essas relações foram investigadas de modo separado, como se um tipo de relação não gerasse nem fosse engendrado no outro.

Kergoat (2010) advoga que as relações sociais devem ser entendidas como consubstanciais e coextensivas, o que implica em fazer uma leitura da realidade social percebendo e concedendo relevo ao entrecruzamento dinâmico e complexo do conjunto de relações sociais. Os termos consubstancialidade e coextensividade chamam a atenção para o fato de que as relações sociais se interagem, se estruturam e se imprimem mutuamente, havendo um relacionamento intrínseco de umas com as outras a despeito de serem componentes de um sistema contraditório e marcado por tensões.

A realidade social pode também ser lida operacionalizando o conceito de interseccionalidade. O conceito de interseccionalidade alerta para o fato de que as vulnerabilidades femininas são mais pujantes que a simples soma do racismo com o sexismo e classicismo. A interseccionalidade, portanto, procura abarcar múltiplas formas de identidade, e, a forma que as relações sociais se transversalizam. Esse conceito tenta atar os efeitos estruturais e dinâmicos da interação entre dois ou mais eixos da subordinação, com relevo para o modo pelo qual o racismo, o patriarcado, e outros sistemas discriminatórios concebem dissimetrias básicas entre as mulheres (CRENSHAW, 2002). Para Crenshaw (1989), uma interdependência marca as relações de poder de raça, sexo e classe, fazendo com que relações interseccionais restrinjam ou potencializem as trajetórias de vulnerabilidade das pessoas.

A analogia dos indivíduos como vias de trânsito possibilita a compreensão de que diferentes opressões se cruzam, sendo a posição social das pessoas produzida nesse entrecruzamento (CRENSHAW, 2002). Notadamente, atributos como raça, classe, gênero, sexualidade, etnicidade, nação, habilidade e idade operam como fenômenos que se delineiam de modo recíproco, dando forma as desigualdades sociais complexas (COLLINS, 2009, 2015).

Hirata (2014) aponta que tanto o conceito de Kergoat (2010) como o de Crenshaw (1989), a despeito de suas diferenciações e controvérsias, possibilitam o avanço no conhecimento da dinâmica e das interfaces das relações sociais e o enfrentamento as polivalentes formas de opressão. Todavia, Kergoat (2010) ressalta que o conceito de interseccionalidade é limitado, uma vez que alguns aspectos das relações sociais são desconsiderados ou considerados de forma insuficiente. A autora aponta que o conceito de interseccionalidade de Crenshaw dificulta pensar que as relações sociais são móveis e historicamente determinadas.

O feminismo negro, por seu turno, advoga o conceito de interseccionalidade, que ganhou corpo nos países anglo-saxônicos. O feminismo negro teve um papel proeminente na desconstrução do pseudouniversalismo das grandes teorias, da concepção de homogeneidade das mulheres e da noção de uma solidariedade e fraternidade entre as mulheres (KERGOAT, 2010). Para Collins (2009), o pensamento feminista negro comporia um leque de experiências e ideias compartilhadas por mulheres afrodescendentes, cuja as interpretações teóricas são empreendidas conforme um ângulo particular de visão de si, da comunidade e da sociedade, ou seja, uma leitura da realidade das mulheres negras por aquelas que a vivem. $\mathrm{O}$ feminismo negro desponta como um espaço de disputa das mulheres negras, latino-americanas, do terceiro-mundo, das ex-colônias e lésbicas que não se sentiam representadas no feminismo, uma vez que o movimento era considerado como um espaço de mulheres brancas, heterossexuais (MARIANO, 2005).

O movimento feminista perdeu, de longa data, poder explicativo sobre a condição de vida de tantas mulheres por não se fazer capaz de reconhecer a contínua marginalidade que marca as mulheres negras e a opressão proveniente de outras ideologias discriminatórias que são dominantes como o racismo (CRENSHAW, 1989; HOOKS, 1984; SAUNDERS; DARITY, 2003). No cenário de sociedades multirraciais, pluriculturais e racistas - como são as sociedades latino-americanas - comparece como eixo basilar na definição de hierarquia de gênero o racismo e seu efeito sobre as relações de gênero (CARNEIRO, 2001). Logo, as assimetrias provenientes da histórica hegemonia masculina não são capazes de serem equacionadas sem a superação de ideologias complementares do sistema de opressão, como o racismo (CARNEIRO, 2001; CRENSHAW, 1989).

Com o feminismo negro aflora a negativa dos discursos que valorizam o gênero ou à classe em relação a outros marcadores identitários, questionando tanto a hierarquização das desigualdades como sua análise descasada. $\mathrm{O}$ feminismo negro põe em xeque a ideia de homogeneidade entre as mulheres, questionando a noção 
de identidade comum a qual orientava as ações políticas de forma neutra (PINHEIRO, 2016). As experiências das mulheres negras deram uma nova tônica ao movimento feminista, dado abordarem as relações familiares e as relações de trabalho de uma perspectiva que não encontrava amparo ou não tinha proeminência na produção das feministas brancas (BIROLI; MIGUEL, 2015).

Em que pese o fato de que todas as mulheres, em alguma medida, sofrem o peso da discriminação de gênero, outros fatores identitários, tais como classe, casta, raça, cor, etnia, religião, origem nacional e orientação sexual, delineiam vivências distintas de discriminação e opressão (CRENSHAW, 2002). A posição social diferenciada e, em certa medida, o privilégio de algumas mulheres, escamoteia a manutenção das problemáticas advindas de uma desigual divisão sexual do trabalho. Portanto, o entendimento das mulheres como categoria homogênea pode invisibilizar no privilégio vivenciado por algumas as contínuas desvantagens que marcam a vida das outras e as relações sociais que as diferenciam, sendo nesse quesito que a questão de classe se ressai.

As desigualdades de classe possibilitam, para algumas mulheres, a mediação da tensão na alocação de tempo entre trabalho e família através da obtenção no mercado dos serviços de cuidados e de tarefas domésticas (MELO; DI SABBATO, 2011), gerando experiência diversificada na forma e no tempo de provisão de cuidados conforme a classe social. A renda cria clivagens objetivas entre as famílias, nas quais os homens de classe média e alta também compartilham da experiência ao vivenciarem a redução da tensão com as mulheres que acessam no mercado os serviços de cuidado e de atividades domésticas (BIROLI, 2016; HOOKS, 1984). A condição econômica concebe privilégio, para um grupo de mulheres, ao possibilitar suavização, simultaneamente, das tensões nos dois polos da divisão sexual do trabalho. A renda propicia a mitigação das responsabilidades familiares e abre brechas para maior e melhor inserção feminina no mercado de trabalho.

Assim, é cada vez mais consensual que investigar a posição social das mulheres sem considerar a raça e classe é ter uma análise parcial da vulnerabilidade feminina. Posto isso, o texto se presta a evidenciar as mulheres enquanto sujeito multifacetado.

\section{Mercado de trabalho e cuidado: experiência diversificada entre as mulheres}

Pensar em termos de uma divisão sexual do trabalho tem elucidado a posição diferenciada que homens e mulheres ocupam na sociedade. Todavia, os avanços possibilitados pela teorização e exposição de uma divisão sexual do trabalho não dispensam a demanda pela compreensão de como a raça e classe comparecem como princípios reguladores nas relações sociais entre os sexos, o que é envidado nessa seção. Para tanto, se acessou como metodologia as estatísticas descritivas de indicadores selecionados sobre mercado de trabalho e cuidado, que foram avaliados a partir do cotejamento da cor (negras ${ }^{1}$ versus brancas), classe (pobres - as que se encontravam nos domicílios $20 \%$ mais pobres- versus ricas - as que se encontravam nos domicílios $20 \%$ mais ricos) e, interseccional (cor e classe cruzadas). Utilizou-se os valores médios das variáveis ou sua frequência absoluta e, no caso, das taxas o cálculo foi feito com base na conceituação do Instituto Brasileiro de Geografia e Estatística (IBGE). O software estatístico empregado foi o Stata 14. Como base de dados acessou-se a Pesquisa Nacional por Amostra de Domicílios Contínua (PNAD Contínua) anual, para o ano de 2018 e, a entrevista 5, porque é a que contém informações sobre cuidados.

A despeito dos avanços galgados pelas mulheres em sua atuação econômica, há padrões diferenciados de inserção laboral percebidos na interseccionalidade de marcadores identitários, como expostos a seguir. Começando pelo indicador de atuação laboral nota-se que as taxas de participação divergem conforme a cor e classe das mulheres, como mostra o Gráfico 1. Em 2018, a diferença de participação econômica das mulheres negras frente às brancas foi de 2 pontos percentuais (pp) a menos para as primeiras. Diferença que é bem mais expressiva cotejando a classe, nada menos que 23 pp desfavoráveis às pobres. $\mathrm{O}$ espaço ocupado pelas mulheres nas relações de trabalho está correlacionado com a divisão do trabalho doméstico não remunerado, a divisão do trabalho remunerado e as relações de poder nas sociedades contemporâneas (BIROLI, 2016), o que deve amparar esses achados desfavoráveis às negras e aos pobres grupos historicamente mais marginalizados. E no caso da classe, a diferença de atuação laboral expressiva em muito deve ser proveniente da ausência de políticas públicas que possibilitem a articulação entre trabalho e família. Como serviços privados de cuidados apresentam custos elevados, ao não contar com o aparato público, muitas das vezes, a opção mais factível para as mulheres mais pobres é não atuar no mercado de trabalho em prol do cuidado da família. A divisão 
Gráfico 1 - Taxa de participação feminina na força de trabalho por cor e classe, Brasil, 2018

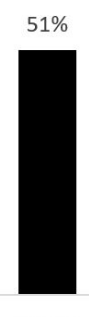

Negras

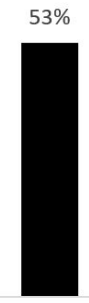

Brancas

Cor

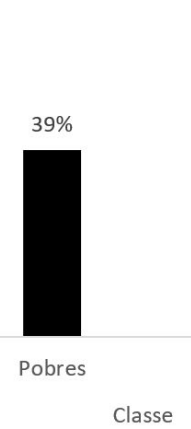

Ricas

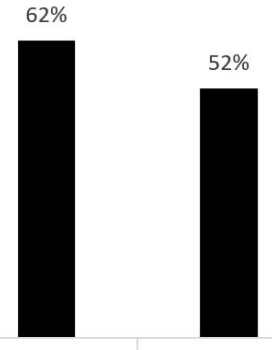

Geral

Fonte: Elaborado pela autora com base na PNAD Contínua (2018).

sexual do trabalho, assim, penaliza de modo mais acentuado as mulheres pobres, dado que as trabalhadoras com maior escolaridade dispõem de recursos para arcar com serviços de cuidados privados (GUEDES, 2015).

Quando o olhar é direcionado a interseccionalidade da cor e classe, como mostra a Tabela 1, nota-se que independentemente da cor a taxa de participação das pobres ficou em torno de $40 \%$. Fato que não ocorreu em relação à riqueza, na qual as negras ricas apresentaram 5 pp maior de atuação que as brancas. Esse resultado vai ao encontro dos apontamentos do feminismo negro de que as mulheres de cor historicamente estão no mercado de trabalho. Mas, que sua atuação é obstaculizada pelo racismo velado que, certamente, alcança em menor intensidade as negras do estrato superior de renda.

Tabela 1 - Taxa de participação feminina na força de trabalho, interseccional, Brasil, 2018

\begin{tabular}{c|c|c|c}
\hline \multicolumn{3}{|c}{ Cor/classe } \\
\hline Negras pobres & Negras ricas & Brancas pobres & Brancas ricas \\
\hline $40 \%$ & $65 \%$ & $40 \%$ & $60 \%$ \\
\hline
\end{tabular}

Fonte: Elaborado pela autora com base na PNAD Contínua (2018).

A diferença entre as mulheres se faz presente também na desocupação. Como mostra o Gráfico 2, as mulheres negras apresentaram maior taxa de desocupação (17\%) do que as brancas (12\%), fato percebido também, embora de modo bem mais acentuado, em relação à classe. Das mulheres pobres economicamente ativas $42 \%$ estavam desocupadas, em 2018, ao passo que apenas $4 \%$ das ricas encontravam-se nessa situação. Desde 2014 o País atravessa uma crise econômica que tem refletido em maiores taxas de desocupação, sendo esses números sugestivos de quem é mais penalizado pela piora do mercado de trabalho.

\section{Gráfico 2 - Taxa de desocupação feminina por cor e classe, Brasil, 2018}

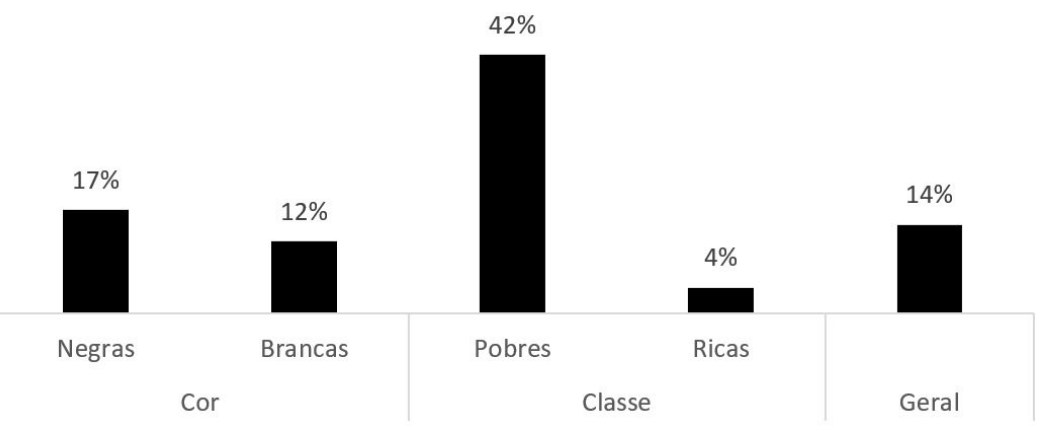

Fonte: Elaborado pela autora com base na PNAD Contínua (2018). 
Na interseccionalidade de cor e classe, percebe-se, na Tabela 2, que a taxa de desocupação das ricas foi aproximadamente $4 \%$ para qualquer cor. Já para as pobres, as mulheres brancas apresentaram uma taxa de desocupação 3 pp maior que as negras. Esse resultado é curioso na medida em que se esperava que as negras pobres fossem mais alijadas nas oportunidades. Outros elementos como o maior quantitativo de filhos a sustentar, maior acesso a redes de apoio comunitárias, e maior precariedade dos postos de trabalho que assumem podem, em alguma medida, explicar porque as negras pobres não são as campeãs da desocupação.

Tabela 2 - Taxa de desocupação feminina interseccional, Brasil, 2018

\begin{tabular}{c|c|c|c}
\hline \multicolumn{4}{|c}{ Cor/classe } \\
\hline Negras pobres & Negras ricas & Brancas pobres & Brancas ricas \\
\hline $41 \%$ & $4 \%$ & $44 \%$ & $4 \%$ \\
\hline
\end{tabular}

Fonte: Elaborado pela autora com base na PNAD Contínua (2018).

Em relação à formalização no trabalho, como mostra o Gráfico 3, as negras estavam também em desvantagem frente às brancas e frente à média geral das mulheres, sendo a diferença, no primeiro caso, de 13 pp. Para a classe a diferença é gritante: $27 \%$ das pobres tinham carteira de trabalho assinada ao passo que $75 \%$ das ricas contavam com essa proteção trabalhista. Se com a legislação atual, tida como mais rígida, a proteção trabalhista não é uma realidade para muitas mulheres, é preocupante a majoração da precarização do trabalho feminino que deve acompanhar a reforma trabalhista aprovada, em 2017, no Congresso Nacional (Lei no 6.787/16) (BRASIL, 2016).

\section{Gráfico 3 - Proporção de mulheres com carteira assinada por cor e classe, Brasil, 2018}

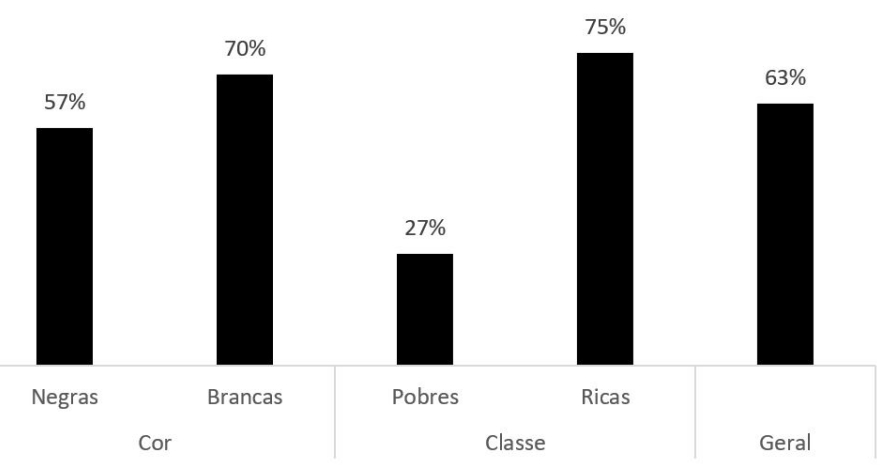

Fonte: Elaborado pela autora com base na PNAD Contínua (2018).

Quando se intersecciona os dados percebe-se que as negras pobres foram as mais mal posicionadas, sendo que apenas $25 \%$ contavam com carteira de trabalho assinada, em 2018. As brancas ricas, de modo oposto, se destacam na alta proteção laboral. Ou seja, $78 \%$ das brancas ricas eram trabalhadoras formais (Ver Tabela 3).

Tabela 3 - Proporção feminina interseccional de carteira assinada, Brasil, 2018

\begin{tabular}{c|c|c|c}
\hline \multicolumn{3}{|c}{ Cor/classe } \\
\hline Negras pobres & Negras ricas & Brancas pobres & Brancas ricas \\
\hline $25 \%$ & $70 \%$ & $31 \%$ & $78 \%$ \\
\hline
\end{tabular}

Fonte: Elaborado pela autora com base na PNAD Contínua (2018). 
Completando o quadro das diferenças femininas no mercado de trabalho tem-se os rendimentos laborais, mostrados na Tabela 4. As mulheres negras tiverem menor rendimento laboral que as mulheres brancas e que a média geral das mulheres. A diferença de ganhos entre as mulheres negras e brancas, em 2018, foi de $\mathrm{R} \$ 892,6$ a menos para as primeiras. No quesito classe, obviamente, a diferença é bem mais expressiva. Uma mulher considerada pobre chega a ter um rendimento laboral quase sete vezes inferior ao da rica. Esses dados refletem e são ao mesmo tempo reflexo da assombrosa desigualdade econômica que marca o Brasil. As assimetrias salariais que marcam o mercado de trabalho brasileiro são a muito pronunciadas, o que chama atenção aqui é o fato de a média salarial das mulheres pobres não alçar se quer o salário mínimo. O fato corrobora a demasiada precarização laboral desse grupo de mulheres, que não usufruem pelo seu trabalho remunerado do valor ao qual a Constituição de 1988 atribuiu como o mínimo social de sobrevivência.

Tabela 4 - Rendimento médio do trabalho habitual principal feminino por cor e classe, Brasil, 2018

\begin{tabular}{c|c|c|c|c}
\hline \multicolumn{2}{c|}{ Cor } & \multicolumn{2}{c}{ Classe } & \multirow{2}{*}{ Geral } \\
\cline { 1 - 3 } Negras & Brancas & Pobres & Ricas & \multirow{2}{1.800,26}{} \\
\hline $1.369,18$ & $2.261,78$ & 516,14 & $3.564,24$ & $\mathbf{1 0 0}$ \\
\hline
\end{tabular}

Fonte: Elaborado pela autora com base na PNAD Contínua (2018).

Quando se cruza cor e classe os dados mostram os extremos opostos que negras pobres e brancas ricas ocupam, o que de maneira nenhuma é novidade. Enquanto as negras pobres, em 2018, tiverem um rendimento médio que se quer alçou o valor do salário mínimo (SM), as brancas ricas, em média, tiverem recebimentos de quase 3 SM, como mostra a Tabela 5. Não se sustenta, por esse e todos os indicadores mostrados, uma vulnerabilidade unívoca feminina no mercado de trabalho. As mulheres vivenciam de forma distinta a vida profissional, sendo que os padrões diferenciados comprometem de forma específica as mulheres negras (LIMA; RIOS; FRANÇA, 2013; ABRAMO, 2006).

Tabela 5 - Rendimento médio do trabalho habitual principal feminino interseccional, Brasil, 2018.

\begin{tabular}{c|c|c|c}
\hline \multicolumn{4}{|c}{ Cor/classe } \\
\hline Negras pobres & Negras ricas & Brancas pobres & Brancas ricas \\
\hline 500,95 & $3.044,60$ & 564,11 & $3.791,19$ \\
\hline
\end{tabular}

Fonte: Elaborado pela autora com base na PNAD Contínua (2018).

Nos cuidados do lar será que a experiência também é diferenciada pela cor e classe? A despeito de serem os estudos sobre uso do tempo que tiram da penumbra a dupla jornada de trabalho feminino, possibilitando a investigação dos cruzamentos entre trabalho remunerado e não remunerado, e, a vida cotidiana das mulheres (CARRASCO, 2006; DONATH, 2000; FONTOURA et al., 2010), o Brasil ainda não conta com uma ampla pesquisa de uso do tempo. $\mathrm{O}$ que se tem à disposição nas pesquisas domiciliares do Brasil são apenas algumas perguntas sobre cuidados e afazeres domésticos. Certamente, as poucas informações disponíveis impedem uma melhor configuração da situação das atividades reprodutivas e, sua diferenciação entre as mulheres.

Mas, valendo-se das informações que se têm, o Gráfico 4 mostra que uma maior proporção de mulheres negras autodeclarou exercer cuidados do que brancas, diferença de $7 \mathrm{pp}$. Mas é, no quesito classe que a diferença se acerba, nada menos do que 29 pp desfavoráveis as pobres. Como já é bem relatado na literatura, as mulheres ricas contam com a possibilidade de terceirizar os cuidados, seja de modo institucional (creches, escolas, Instituições de Longa Permanência para Idosos) ou outros arranjos (empregadas domésticas, babás, diaristas). Ao poder terceirizar o cuidado mitiga-se a tensão da articulação entre trabalho e família, abrindo brechas para uma maior e melhor inserção laboral, como os dados supracitados confirmam. 
Gráfico 4 - Proporção de mulheres que realizou tarefas de cuidados de moradores do domicílio ou fora do domicílio, por cor e classe, Brasil, 2018

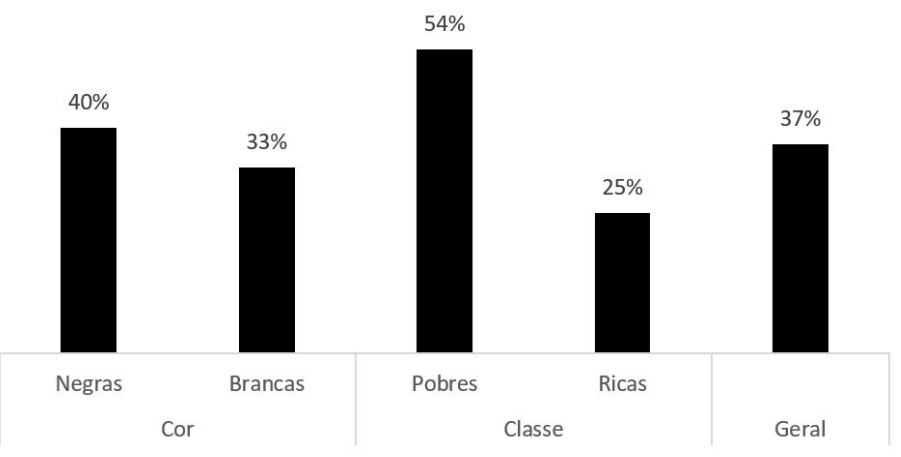

Fonte: Elaborado pela autora com base na PNAD Contínua (2018).

Quando a atenção é debruçada sobre a interseccionalidade nota-se que as campeãs na provisão de cuidados foram as negras pobres com $54 \%$ de participação, seguidas pelas brancas pobres com $51 \%$. Entre as ricas, a cor não compareceu como diferencial, mas a proporção que declarou exercer cuidados é bem mais baixa $(25 \%)$, ver Tabela 6.

Uma grande vantagem da PNAD Contínua foi a coleta separada sobre as informações de cuidados e afazeres domésticos. Essa diferenciação mostrou que a proporção de quem realiza cuidado é bem menor do que em relação aos afazeres domésticos, mas que cor e classe são fatores que marcam gradações desses quesitos.

O Gráfico 5 mostra que a proporção de mulheres negras que realizaram afazeres domésticos foi maior do que a de brancas, assim como para as pobres foi maior que para as ricas. Mas, as diferenças, nos dois casos, foram de pequena monta. A proporção acima dos $90 \%$ para todas as categorias de mulheres não surpreende na medida em que, conforme normas de gênero arraigadas, as atividades domésticas seguem sendo responsabilidade feminina.

Tabela 6 - Proporção interseccional de mulheres que realizou tarefas de cuidados de moradores do domicílio ou fora do domicílio

\begin{tabular}{c|c|c|c}
\hline \multicolumn{4}{|c}{ Cor/classe } \\
\hline Negras pobres & Negras ricas & Brancas pobres & Brancas ricas \\
\hline $54 \%$ & $25 \%$ & $51 \%$ & $25 \%$ \\
\hline
\end{tabular}

Fonte: Elaborado pela autora com base na PNAD Contínua (2018).

Gráfico 5 - Proporção de mulheres que realizou tarefas domésticas para o próprio domicílio ou em domicílio de parentes, por cor e classe, Brasil, 2018

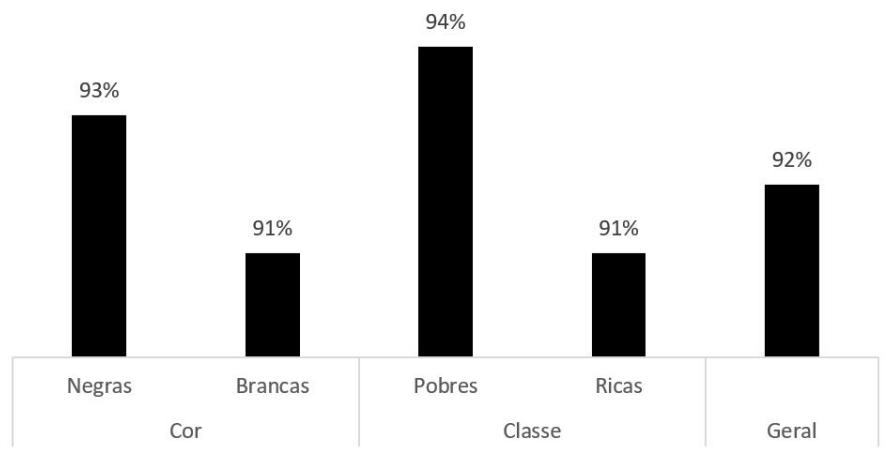

Fonte: Elaborado pela autora com base na PNAD Contínua (2018). 
A interseccionalidade, mostrada na Tabela 7, revela que as negras pobres e as brancas ricas mais uma vez estão em polos opostos, mas com distinção pouco acentuada. Ou seja, as que se destacam no trabalho reprodutivo no Brasil, ainda hoje, são as negras pobres. Com fruto de um passado escravocrata, é perene no imaginário social que a função das negras é servir a outrem não surpreendendo sua maior representação nas atividades vinculadas aos cuidados.

Tabela 7 - Proporção de mulheres que realizou tarefas domésticas para o próprio domicílio ou em domicílio de parentes, interseccional, Brasil, 2018

\begin{tabular}{c|c|c|c}
\hline \multicolumn{4}{|c}{ Cor/classe } \\
\hline Negras pobres & Negras ricas & Brancas pobres & Brancas ricas \\
\hline $94 \%$ & $92 \%$ & $93 \%$ & $91 \%$ \\
\hline
\end{tabular}

Fonte: Elaborado pela autora com base na PNAD Contínua (2018).

Por fim, cabe apresentar na Tabela 8 a jornada destinada as tarefas do lar. O primeiro elemento a destacar é que as mulheres, independente da categoria, tiveram uma jornada elevada de trabalho reprodutivo - por volta de 20 horas semanais. Existiu diferença de cor, mas foi pouco acentuada. Chamou a atenção a distinção de classe, com as ricas tendo despendido cinco horas semanais a menos nas atividades do lar do que as pobres. Como aponta Passos e Guedes (2018), o modelo de delegação, no qual algumas mulheres atribuem a outras as atividades reprodutivas faz parte da realidade brasileira, embora de modo menos acentuado do que o modelo de conciliação, em que as mulheres com pouco auxílio dos homens e do estado têm que equilibrar o trabalho produtivo e reprodutivo. É esse modelo de delegação que possibilita as mulheres ricas mitigarem seu tempo de atividades domésticas e cuidados.

Tabela 8 - Total de horas semanal que as mulheres dedicaram a tarefas de cuidado de pessoas e/ou afazeres domésticos, por cor e classe, Brasil, 2018

\begin{tabular}{c|c|c|c|c}
\hline \multicolumn{2}{c|}{ Cor } & \multicolumn{2}{c}{ Classe } & \multirow{2}{*}{ Geral } \\
\hline Negras & Brancas & Pobres & Ricas & 21 \\
\hline 22 & 21 & 24 & 19 & 21 \\
\hline
\end{tabular}

Fonte: Elaborado pela autora com base na PNAD Contínua (2018).

Ao se interseccionar cor e classe, a Tabela 9 mostra que no quesito jornada de trabalho reprodutivo as brancas pobres ficaram mais mal posicionadas, embora a diferença seja de apenas uma (1) hora a mais que as negras pobres. A diferença entre as ricas negras e brancas também foi de uma (1) hora semanal, porém a mais para as negras ricas. Talvez na pobreza haja maior solidariedade nos cuidados entre as mulheres de cor, mas essa é uma hipótese que carece de investigação empírica.

Tabela 9 - Total de horas semanal que as mulheres dedicaram a tarefas de cuidado de pessoas e/ou afazeres domésticos, interseccional, Brasil, 2018

\begin{tabular}{c|c|c|c}
\hline \multicolumn{4}{c}{ Cor/classe } \\
\hline Negras pobres & Negras ricas & Brancas pobres & Brancas ricas \\
\hline 23 & 19 & 24 & 18 \\
\hline
\end{tabular}

Fonte: Elaborado pela autora com base na PNAD Contínua (2018). 
Os dados analisados possibilitam duas conclusões. Primeiro, que as mulheres compõem um sujeito multifacetado, no qual a experiência tem gradientes conforme classe e raça. Segundo, que a classe imprime maior intensidade nas gradações que a raça. Assim, é contraproducente considerar as mulheres uma categoria homogênea, pois há muitas pistas que o cruzamento de fatores identitários colorem em tons distintos a opressão de ser mulher. E, nesse intercruzamento, ser negra e pobre parece potencializar vulnerabilidades.

\section{Considerações Finais}

As normas de gênero são construídas histórica e culturalmente nas relações sociais assimétricas e nas relações de poder entre os sexos. Nessa modelagem de papéis e funções sociais assimétricos coube à mulher um lugar social mais subalterno. Por trás do discurso de que as mulheres têm personalidade amorosa, frágil, protetora escondem-se concepções que identificam a mulher com a função de cuidadora. Essa atribuição "naturalizada" do cuidado ao ser feminino vem marcando desvantagens históricas para atuação econômica e social das mulheres, uma vez que o cuidado restringe a disposição e o tempo das mulheres para a vivência fora da família.

Todavia, deve-se ressaltar a heterogeneidade das mulheres. Os dados de mercado de trabalho e atividades domésticas e de cuidados mostram que as mulheres negras brasileiras se encontram em situação mais precarizada frente às mulheres brancas, em um amplo leque de indicadores. Certamente, a justaposição de preconceitos e discriminações, referentes a ser mulher e ser negra, deve amparar a desvantagem desse contingente populacional.

As mulheres ricas, embora não escapem dos papéis sociais definidos ao ser feminino, podem se valer do modelo de delegação contratando outras mulheres para exercerem as atividades do lar e têm acesso à creche e escola privada para manter seus filhos, bem como podem acessar cuidados formais para os idosos. A possibilidade de comprar no mercado os serviços de cuidados atenua para mulheres mais bem posicionadas financeiramente as responsabilidades inerentes ao ser feminino, gerando experiências distintas nas assimetrias de gênero conforme a classe social. Em outras palavras, as mulheres pobres ao não terem à disposição robustas políticas públicas de articulação entre trabalho e família encontram diversas barreiras para seu desenvolvimento profissional, tendo à disposição apenas limitado leque de oportunidades de inserção e permanência no mercado de trabalho.

Em que pese às normas de gênero alcançarem todas as mulheres, os dados brasileiros evidenciam que os efeitos comportam gradações de acordo com outros fatores identitários. As diferenças mais acentuadas ocorrem devido à posição de classe, mas a cor também imprimi distinções marcantes na inserção laboral e nos cuidados. Nesse intercruzamento de vulnerabilidades, as pobres negras, em linhas gerais, se ressaem.

Essa experiência diversificada feminina deve ser delatada, de modo que a atuação do estado não seja cega ou neutra perante essas desigualdades. A promoção da cidadania inclusiva para as mulheres passa pelo o enfrentamento das assimetrias entre homens e mulheres e entre as mulheres e seus efeitos deletérios na vivência social e profissional. Assim sendo, a ampliação da proteção dos direitos humanos para as mulheres demanda a percepção e compreensão de que a interseccionalidade do gênero com outros fatores identitários delineiam vulnerabilidades e experiências peculiares. Intervenções públicas e proteções mais eficazes passam, portanto, pela avaliação detalhada de como raça e classe posicionam as mulheres de modo distinto na sociedade, para a qual este texto procurou trazer uma modesta contribuição.

\section{Referências}

ABRAMO, L. Desigualdade de gênero e raça no mercado de trabalho brasileiro. Cienc. Cult, São Paulo, v. 58, n. 4, p. 40-41, out./ dez. 2006.

BIROLI, F. Divisão sexual do trabalho e democracia. DADOS: Revista de Ciências Sociais, Rio de Janeiro, v. 59, n. 3, p. 719-681, jul./set. 2016.

BIROLI, F; MIGUEL, L. F. Gênero, raça, classe: opressões cruzadas e convergências na reprodução das desigualdades. Mediações, Londrina, v. 20, n. 2, p. 27-55, jul./dez. 2015.

BRASIL. Câmara dos Deputados. Projeto de Lei no 6.787/2016. Altera o Decreto-Lei no 5.452, de $1^{\circ}$ de maio de 1943 - Consolidação das Leis do Trabalho, e a Lei $n^{\circ}$ 6.019, de 3 de janeiro de 1974, para dispor sobre eleições de representantes dos trabalhadores no 
local de trabalho e sobre trabalho temporário, e dá outras providências. 23 dez. 2016. Disponível em: https://www2.camara.leg.br/ atividade-legislativa/discursos-e-notas-taquigraficas/discursos-em-destaque/projeto-de-lei-no-6787-2016-reforma-trabalhista/projetode-lei-no-6787-2016-reforma-trabalhista. Acesso em: 8 set. 2020.

CARNEIRO, S. Enegrecer o feminismo: a situação da mulher negra na América Latina a partir de uma perspectiva de gênero. Revista LOLA Press, nº 16, nov. 2001.

CARRASCO, C. La economía feminista: una apuesta por otra economia. In: VARA, M. J. (org.), Estudios sobre Género y Economía. Madrid: Akal, 2006. p. 29-62.

COLLINS, P. H. Black Feminist Thought. New York/London: Routledge. 2009.

COLLINS, P. H. Intersectionality's Definitional Dilemmas. Annu. Rev. Sociol, v. 41, pp. 1-20, 2015.

CRENSHAW, K. Demarginalizing the intersection of race and sex: a black feminist critique of discrimination doctrine, feminist theory and antiracist politics. University of Chicago Legal Forum, v. 8, pp. 139-167, 1989.

CRENSHAW, K. Documento para o encontro de especialistas em aspectos da discriminação racial relativos ao gênero. Estudos Feministas, Florianópolis, v.10, n.1, p. 171-188, 2002.

DONATH, S. The other economy: a suggestion for a distinctively feminist economics. Feminist Economics, v. 6, n. 1, p.115-123, 2000. FONTOURA, N. et al. Pesquisas de uso do tempo no Brasil: contribuições para a formulação de políticas de conciliação entre trabalho, família e vida pessoal. Revista Econômica, Niterói, v. 12, n. 1, p. 11-46, jun. 2010.

GUEDES, M. Heterogeneização da mão de obra feminina: o que mudou no período recente? Gênero, Niterói, v.15, n.2, p. 139-154, 1. sem. 2015.

HIRATA, H. Gênero, classe e raça: interseccionalidade e consubstancialidade das relações sociais. Tempo Social, São Paulo, v. 26, n. 1, jun. 2014.

HOOKS, B. Feminist theory from margin to center. Boston: South End Press, 1984.

IBGE. Pesquisa Nacional Por Amostra de Domicílios Contínua, 2018. Disponível em: https://www.ibge.gov.br/estatisticas/downloadsestatisticas.html?caminho=Trabalho_e_Rendimento/Pesquisa_Nacional_por_Amostra_de_Domicilios_continua/Anual/Microdados/ Visita. Acessado em: 15 de janeiro de 2020.

KERGOAT, D. Dinâmica e consubstancialidade das relações sociais. Novos Estudos CEBRAP, São Paulo, n. 86, p. 93-103, 2010. KERGOAT, D. Divisão sexual do trabalho e relações sociais de sexo. In: HIRATA, H. et al. (org.). Dicionário Crítico do feminismo. São Paulo: Unesp, 2009, p. 67-75.

LIMA, M.; RIOS, F.; FRANÇA, D. Articulando gênero e raça: a participação das mulheres negras no mercado de trabalho (19952009). In: MARCONDES, M. M. et al. Dossiê mulheres negras: retrato das condições de vida das mulheres negras no Brasil. Brasília: Ipea, 2013.

MARIANO, S. A. O sujeito do feminismo no pós-estruturalismo. Estudos Feministas, Florianópolis, v. 3, n. 13, p. 483-505, set./dez. 2005. MELO, H. P.; DI SABBATO, A. Divisão sexual do trabalho e pobreza. In: MELO, H. P.; DI SABBATO, A. Autonomia e empoderamento da mulher. Brasília: Fundação Alexandre Gusmão, 2011. p. 53-76.

PASSOS, L.; GUEDES, D. R. Participação feminina no Mercado de trabalho e a crise de cuidados da modernidade: conexões diversas. Planejamento e Políticas Públicas, v. 1, n. 50, 2018.

PINHEIRO, L. S. Os dilemas da construção do sujeito no feminismo da pós-modernidade. Texto para discussão/Instituto de Pesquisa Econômica Aplicada (IPEA). Rio de Janeiro, 2016.

SAUNDERS, L.; DARITY, W. Feminist theory and racial economic inequality. In: FEBER, M.; NELSON, J. (org.). Feminist economics today: Beyond economic man. Chicago: The University of Chicago Press, 2003.

\section{Nota}

1 A categoria negra considera pretas e pardas.

\section{Luana Passos}

luanapassos_s@hotmail.com

Doutora em economia pela Universidade Federal Fluminense (UFF)

Professora na Universidade Federal do Oeste da Bahia (UFOB) 


\section{UFOB}

Rua Bertioga, 892- Morada Nobre I

Barreiras - BA, Brasil

CEP: 47810-059

\section{Lorena Passos de Souza}

lorenapassos.09@gmail.com

Licenciada em Biologia pela Universidade Federal do Recôncavo da Bahia (UFRB)

Mestranda em Recursos Genéticos Vegetais pelo Programa de Pós-graduação em Recursos Genéticos

Vegetais da Universidade Federal do Recôncavo da Bahia (UFRB)

\section{UFRB}

R. Rui Barbosa, 710, Centro

Cruz das Almas - BA - Brasil

CEP:44380-000

\section{Agradecimentos}

Agradecemos as sugestões das debatedoras do GT 32 do XXI

Encontro da ABEP, que contribuíram para o aprimoramento do texto. As eximimos de qualquer responsabilidade pelo resultado final.

Agência financiadora

Não se aplica.

Contribuições das autoras

Luana Passos - Concepção, redação do manuscrito, análise de dados, discussão de resultados. Lorena Souza - Preparação de dados, elaboração dos gráficos e tabelas, análise de dados, formatação.

Aprovação por Comitê de Ética e consentimento para participação

Não se aplica.

Consentimento para publicação

Consentimento das autoras.

Conflito de interesses

Não há conflito de interesses. 